\title{
IUS VOCATIO
}

Revista de Investigación de la Corte Superior de Justicia de Huánuco

Vol. 4, n. ${ }^{\circ}$ 4, enero-diciembre, 2021, 39-53

Publicación anual. Huánuco, Perú

ISSN: 2810-8043 (En línea)

DOI: 10.35292/iusVocatio.v4i4.544

\section{PRINCIPIOS JURÍDICOS PARA EL DISEÑO DE UNA POLÍTICA CRIMINAL CONTRA LA CORRUPCIÓN EN EL ESTADO CONSTITUCIONAL DE DERECHO}

\section{LEGAL PRINCIPLES FOR THE DRAFTING OF A CRIMINAL POLICY AGAINST CORRUPTION IN A CONSTITUTIONAL STATE UNDER THE RULE OF LAW}

\author{
JEREMÍAs Rojas VeLÁsQuez \\ Distrito Fiscal de Huánuco \\ (Huánuco, Perú) \\ Contacto: jeremphco@gmail.com \\ https://orcid.org/0000-0001-6769-4092
}

\section{RESUMEN}

En el presente artículo se plantea la necesidad de diseñar una política criminal integral contra la corrupción, basada en principios jurídicos supranacionales y nacionales en el marco del Estado constitucional de derecho, en aras de restablecer la legitimidad del Estado y el irrestricto respeto de los derechos fundamentales.

Palabras claves: violación de derechos fundamentales; deslegitimación del Estado; política criminal integral. 


\section{ABSTRACT}

This article proposes the development of a comprehensive criminal policy against corruption based on supranational and national legal principles within the framework of the constitutional rule of law. The objective of this proposal is to reinforce the legitimacy of the State and the unrestricted respect for fundamental rights.

Key words: violation of fundamental rights; delegitimization of the State; comprehensive criminal policy.

Recibido: 15/04/2021 Aceptado: 30/07/2021

\section{INTRODUCCIÓN}

Para cumplir sus deberes constitucionales, el Estado diseña la administración pública, mediante la cual garantiza los derechos fundamentales de la persona y busca el bienestar general (artículo 44 de la Constitución Política del Perú). Dicha administración pública se ocupa de las prestaciones de los servicios públicos ejercidos por los funcionarios y los servidores públicos a quienes la Constitución y la ley les encomiendan tales tareas (Arismendiz, 2018). Empero, percibimos que la administración pública es deficiente, lo cual deslegitima al Estado por cuanto dista su actuación de sus deberes constitucionales.

Cabe señalar que la corrupción generalizada en la administración pública es uno de los factores que contribuyen a la realidad mencionada. En esa línea, con bastante acierto, José Burneo (2009) sostiene que «la corrupción afecta y amenaza la vigencia de los derechos humanos» (p. 347); por lo tanto, la prevención y la lucha contra dicho fenómeno son dos medidas impostergables del Estado, las cuales son promovidas por la comunidad internacional en el marco de las normas supranacionales, los tratados o las convenciones. De igual modo, Francisco Macedo (2015) explica que «todos los actos de corrupción vulneran directamente (de por sí) o indirectamente (conducen a la violación) [los] derechos humanos» (p. 141) y afirma que la democracia es el entorno para garantizar estos derechos (p. 142). 
En ese contexto, dado que la corrupción es un problema estructural y sistemático enquistado tanto en la Administración Pública como en el ámbito privado, captó nuestro interés; por ello, en el presente trabajo académico abordamos dicha problemática desde el enfoque jurídico y proponemos un diseño de política criminal para afrontar aquella realidad que vulnera los derechos fundamentales y menoscaba la legitimidad del Estado; en definitiva, planteamos los cimientos básicos para el diseño de una política criminal contra la corrupción.

\section{LA CORRUPCIÓN}

La corrupción es uno de los principales problemas del mundo contemporáneo, pues afecta a los países desarrollados y subdesarrollados, cualquiera sea su sistema social, cultural, económico o político; en ese sentido, el Poder Ejecutivo (2018) la concibe como un fenómeno social que agobia a la comunidad internacional, nacional y local, obstaculizando el desarrollo económico y social de la nación y deslegitimando al Estado (Oficina del Alto Comisionado de las Naciones Unidas para los Derechos Humanos, 2020).

Según Transparencia Internacional, los países más corruptos se encuentran en América Latina y, entre los 180 países, Perú se ubica en el puesto 94 del índice de Percepción de la Corrupción 2020, pues obtuvo 38 puntos.

Según estimaciones que daba la Defensoría del Pueblo el año pasado, el «costo de la corrupción» en el Perú significa cerca del $10 \%$ del presupuesto público anual. Es decir, es afectada la décima parte de los recursos que son destinados a salud, infraestructura, gastos administrativos, seguridad, educación en beneficio de la ciudadanía (Vásquez, 2018, párr. 3).

Dicha percepción refleja cómo la corrupción ha calado en todas las esferas de la Administración Pública, por ejemplo, en el ámbito ejecutivo (expresidentes y exministros investigados por actos de corrupción) y judicial (magistrados involucrados en actos corruptos). 
En el caso específico de la región de Huánuco, la corrupción también se manifiesta; por ello, existen procesos penales contra funcionarios y servidores públicos debido a su participación en actos de corrupción y muchos de ellos se encuentran condenados; esto confirma que la corrupción se ha enquistado en la Administración Pública. A propósito de lo anterior, Alfonso Quiroz (2013) afirma que «la historia del Perú ha sido en parte la historia de sucesivos ciclos de corrupción seguidos por períodos sumamente breves de reforma anticorrupción, interrumpidos por intereses creados contrarios a la reforma» (p. 424). Esta situación puede ser acertadamente descrita mediante la siguiente frase:

Nuestro planeta sufre cada vez más de una enfermedad que como el cáncer corrompe y destruye poco a poco, pero con mucho dolor, desde la más alta hasta la más pequeña de las instituciones sociales.

¡Esa enfermedad es la corrupción! (Orrego, 2018, párr. 1; la cursiva es nuestra)

De esta manera, la corrupción es un mal que concita la intervención no solo de la comunidad jurídica, sino que también requiere la actuación decidida, conjunta y articulada de los entes del Estado y la sociedad civil (Fernández, 2015), diseñando una política criminal orientada a poner a buen recaudo la administración pública, pues esta constituye el medio, por el cual el Estado concretiza el bienestar general de la población (Zúñiga, 2001); por lo tanto, la lucha contra la corrupción exige acciones y estrategias a nivel local, regional, nacional e internacional.

Ahora bien, en la comunidad mundial existe un consenso respecto de la necesidad de perseguir a nivel internacional los casos más graves de corrupción y evitar la impunidad (Ugaz y Hava, 2016).

Al mismo tiempo, los esfuerzos para combatir la corrupción deben respetar los derechos humanos, porque de no hacerlo perderían legitimidad (Oficina del Alto Comisionado de las Naciones Unidas para los Derechos Humanos, 2020); por otro lado, de acuerdo con Carpio (2013), un aspecto que nos permitirá luchar contra la corrupción es la transparencia en la ley y la sociedad en los siguientes términos: 
Para salir de esta espiral creciente y perniciosa hay al menos dos vías: imponer controles externos que hagan que la decisión de corromperse no salga rentable, a través, por ejemplo, de legislación a favor de la transparencia de las instituciones y las administraciones públicas; o un cambio en cómo se percibe el entorno, que la gente transforme su forma de ver la vida y de actuar. Dicho de otra manera, se trata de rendir cuentas a los demás o a la propia conciencia (párr. 26; negritas del original).

En resumen, urge diseñar una reacción frontal contra el fenómeno de la corrupción.

\section{ESQUEMA DE UN POLÍTICA CRIMINAL CONTRA LA CORRUPCIÓN}

Estamos convencidos de que para afrontar firmemente la corrupción es necesario diseñar una política criminal (Borja, 2011) que incorpore la participación conjunta del Estado y la sociedad contra dicho fenómeno en los niveles de prevención, detección, investigación, sanción y erradicación (Casell, 2004). A continuación, exponemos los principios jurídicos ${ }^{1}$ que, desde nuestra perspectiva, se deben considerar.

\subsection{Nivel de los convenios internacionales}

a. Principio de integración internacional en la lucha contra la corrupción Permitirá diseñar una política criminal global basada en el bosquejo de protocolos de cooperación internacional para una adecuada acción de prevención, investigación y sanción contra la corrupción (Luzón, 2016). Esto significa que deben implementarse las buenas prácticas de apoyo del sistema de las Naciones Unidas en los Estados americanos para prevenir y luchar contra la corrupción con énfasis en los derechos humanos.

1 Cabe aclarar que estos principios jurídicos han sido previamente desarrollados en el quinto capítulo de nuestra tesis doctoral Principios jurídicos que diseñan la política criminal contra la corrupción de funcionarios en el Estado constitucional de derecho, en la región de Huánuco. Junio 2011- julio 2018 (Rojas, 2019, pp. 87-99). 
Efectivamente, respecto al actuar en el nivel preventivo, José Burneo (2009) indica que «La internacionalización de la prevención y la lucha contra la corrupción constituye[n] un fenómeno nuevo en las relaciones internacionales, y expresa[n] una seria preocupación por parte de la comunidad internacional que ha sido plasmada positivamente en el derecho internacional» (pp. 346-347).

b. Principio de jurisdicción internacional en la lucha contra la corrupción La creación y la implementación de una Corte Internacional contra la corrupción permitirá que se investiguen y sancionen los actos de corrupción internacional y transnacional, y se procure una efectiva indemnización integral y real del daño causado, el cual, muchas veces, compromete a un Estado o parte significativa de él.

Al respecto, Juan Ferré (2002) afirma que la globalización supone que las políticas criminales nacionales de los Estados ceden espacio en beneficio de las políticas criminales internacionales, lo cual se refleja fundamentalmente en la extraterritorialidad de las disposiciones penales o procesales. A ello se suma la posición sostenida por Kofi Annan (2004), secretario general de las Naciones Unidas:

Si la delincuencia atraviesa las fronteras, lo mismo debería [...] hacer la acción de la ley. Si el imperio de la ley se ve socavado [...] en muchos países, quienes los defienden no se pueden limitar a ampliar únicamente medios y arbitrios nacionales. Si los enemigos del progreso y de los derechos humanos procuran servirse de la apertura y de las posibilidades que brinda la mundialización para lograr sus fines, nosotros [los Estados] debemos servirnos de esos mismos factores para defender los derechos humanos y vencer a la delincuencia, la corrupción y la trata de personas (p. iii).

c. Principio de veto contra la empresa

En la XIV Cumbre de la Alianza del Pacífico, llevada a cabo desde el 1 hasta el 6 de julio de 2019 en Lima (Perú), el presidente colombiano Iván Duque expresó que debía implementarse, a nivel internacional, una lista negra de las empresas que incurrieron en corrupción, con la finalidad de que se les impida contratar en los Estados donde ejecutaron actos de corrupción. 
d. Principio de la recuperación de activos

La sanción contra la corrupción no debe limitarse a determinar la responsabilidad de sus impulsores, sino que también debería procurar la recuperación de activos que son productos de la corrupción. Para que ello sea posible, desde las normas internacionales debe impulsarse la cooperación entre los diversos países. Al respecto, Pedro de la Lama (2002) afirma que uno de los aspectos más importantes en la lucha contra la corrupción y toda la tipología de delitos de índole económica es la intervención o la incautación de aquellos bienes en los que se haya materializado el producto del fraude o, en todo caso, el descubrimiento y la recuperación de los fondos defraudados.

\subsection{Nivel constitucional}

a. Principio de la política pública en la lucha contra la corrupción El Estado debe asumir el mandato constitucional de prevenir, combatir y sancionar todo tipo de corrupción (Proceso Competencial, Expediente n. ${ }^{\circ}$ 006-2006-PC/TC, caso Poder Judicial); el primer paso es incorporar tal mandato en nuestra carta magna y para ello se deben modificar los alcances del artículo 8 de la Constitución Política de 1993, pues dicha norma solo se enfoca en la lucha contra el tráfico ilícito de drogas. Proponemos que, mediante una reforma constitucional, se incorpore la lucha contra la corrupción y la criminalidad organizada.

b. Principio del deber ciudadano de asumir el compromiso social de luchar contra la corrupción

Desde el ámbito constitucional, es imprescindible añadir el deber de todo ciudadano de asumir el compromiso social en la lucha frontal contra la corrupción (Proceso de Inconstitucionalidad, Expedientes n. ${ }^{\text {s }}$ 009-2007-PI/TC y 010-2007-PI/TC, caso Sirumbal Ramos). Este principio sería compatible con los deberes constitucionales del ciudadano previstos en el artículo 38 de la Constitución; esto es, cumplir, respetar y defender la carta magna. Asimismo, dado que esta última reconoce los derechos fundamentales y entendiendo que la corrupción viola tales derechos, consideramos necesario establecer como uno de los deberes constitucionales impostergables de todo ciudadano la prevención y la erradicación de la corrupción en todas sus manifestaciones. 
c. Principio de la imprescriptibilidad de los delitos de corrupción de funcionarios

Si bien mediante la modificatoria del artículo 41 de la Constitución se estableció la imprescriptibilidad de la acción penal en los supuestos más graves de los delitos cometidos contra la Administración Pública, no se especificó en qué delitos operaría tal condición legal; atendiendo al principio de legalidad, consideramos que la imprescriptibilidad de la acción penal debe comprender todos los delitos contra la Administración Pública, debido a que «todo acto de corrupción viola derechos humanos» (Macedo, 2015, p. 62); además, entorpece la esperanza de desarrollo de la persona y el país, en general.

\subsection{Nivel de la política criminal preventiva}

a. Principio de prevención general contra la corrupción Como la corrupción es un problema integral y un fenómeno multicausal, su solución trasciende lo estrictamente legal; por ello,

resulta indispensable adoptar políticas de prevención que apunten a crear y reforzar la institucionalidad, para lo cual se requiere la implementación de una carrera pública basada en la meritocracia de sus funcionarios, con un sistema de incentivos adecuado que privilegie la integridad en la función pública y la eficiencia de los servidores [públicos] (Ugaz, 2010, p. 378).

A partir de dicha evaluación, la lucha contra tal fenómeno debe iniciarse con la prevención; esto significa que quienes gobiernan nuestro país deben procurar el eficiente y eficaz acatamiento del Estado constitucional de derecho, el respeto irrestricto de los derechos fundamentales, la participación efectiva de la sociedad civil — garantizándole el derecho a la información- y la promoción de la responsabilidad, la transparencia y la solidaridad en la Administración Pública.

Asimismo, es preciso reconocer el derecho a vivir en un mundo libre de corrupción para garantizar la realización de los derechos fundamentales en un Estado libre de corrupción. 


\subsection{Enfoque del derecho penal}

a. Principio de la fundamentación constitucional del contenido de los bienes jurídicos tutelados en los delitos de corrupción de funcionarios En principio, debe ampliarse la protección de los bienes jurídicos tutelados, pues la recta administración pública (su transparencia o imparcialidad) no solo debe entenderse como un interés jurídicamente protegido, sino que también se debe dotar de contenido al bien jurídico tutelado desde la óptica de los derechos fundamentales, ya que, según el Consejo Internacional de Políticas de Derechos Humanos (2009), la corrupción endémica destruye los valores fundamentales de la dignidad humana porque atenta contra el derecho a la vida, la libertad, la igualdad, la seguridad y la solidaridad.

En segundo lugar, se debe determinar la reparación civil integral y real por el daño causado (la afectación del bien jurídico), es decir, tomando en cuenta el contenido, el alcance y la dimensión constitucional de los derechos fundamentales. Cabe recalcar que el derecho a una reparación efectiva está garantizado por la mayoría de los tratados internacionales sobre derechos humanos, cuyos textos plantean que, cuando ocurre una violación de derechos humanos, el Estado debe proveer una reparación efectiva a las víctimas. De lo contrario, surgiría un clima de impunidad, lo cual atenta gravemente contra los derechos humanos, especialmente cuando los Estados, regular o intencionalmente, niegan el desagravio.

b. Principio de razonabilidad y proporcionalidad de las penas en los delitos de corrupción de funcionarios

Basándose en la fundamentación constitucional y la protección de bienes jurídicos protegidos en los delitos de corrupción de funcionarios, debe determinarse, en términos cuantitativos y cualitativos, la dosimetría de la pena, tanto en su imposición efectiva como en la imprescriptibilidad de la acción penal y la pena. En otras palabras, en ejercicio de su función legislativa, los congresistas deben establecer penas considerando la protección de los bienes jurídicos según su importancia o naturaleza. A propósito de ello, aclaramos que en una simple lectura del Código Penal identificamos tipos penales que protegen el patrimonio privado, como es el caso del delito de robo agravado, 
cuya pena es sumamente grave en comparación con los delitos de corrupción de funcionarios y el peculado, que consiste en la apropiación del patrimonio del Estado.

c. Responsabilidad administrativa penal de las personas jurídicas

Nuestra legislación ha regulado la responsabilidad penal de las personas jurídicas (empresas) respecto de los ilícitos penales cometidos por sus representantes y cuyos beneficios han recaído en dichas empresas.

Para fortalecer dicha medida, debe implementarse una lista negra o inhabilitar definitivamente a las empresas que incurrieron en actos de corrupción, de modo que nunca más contraten con los Estados, conforme señaló el presidente colombiano Iván Duque en la mencionada XIV Cumbre de la Alianza del Pacífico.

\subsection{Enfoque del derecho procesal penal}

a. Principio del fomento de las competencias o las especialidades en delitos de corrupción

Este principio se enfoca en los operadores del derecho (jueces, fiscales $\mathrm{y}$ abogados) y tiene por objetivo fortalecer sus competencias profesionales o su especialización en el tratamiento de los delitos de corrupción, a fin de que su respuesta o su impartición de la justicia sea eficiente y eficaz en la lucha frontal contra la corrupción.

b. Principio de la promoción de protocolos de actuación interinstitucional entre las instituciones que imparten justicia

Las instituciones comprometidas en la impartición de justicia, representadas por el Poder Judicial, el Ministerio Público, la Contraloría General de la República, la Policía Nacional y la Defensa Pública, deben asumir el compromiso de una actuación conjunta y articulada de todo el Sistema Judicial; para ello, debe procurarse la suscripción de convenios interinstitucionales mediante los cuales se diseñen protocolos de actuación que reflejen una participación efectiva en la lucha contra la corrupción y se respete el derecho a una reparación efectiva por el daño causado. 
Cabe señalar que existe un convenio entre las instituciones antes mencionadas, pero estas se limitaron únicamente a su suscripción; lamentablemente, no se implementó con acciones concretas que viabilicen una actuación conjunta, coherente y articulada desde todos los frentes de la lucha contra la corrupción.

c. Principio del uso de la prueba indiciaria en los delitos de corrupción En el ámbito procesal, se exigen la actuación y la generación de la prueba; lo ideal es obtener la prueba directa de la comisión del delito de corrupción de funcionarios; sin embargo, la praxis judicial demuestra que la actividad probatoria en esta clase de delitos, caracterizados por su clandestinidad, se cimienta en la prueba indiciaria o indirecta, afirmación que se condice con el fundamento 33 del Acuerdo Plenario n. ${ }^{\circ} 3$ - 2010/CJ-116, del 16 de noviembre de 2010, y el fundamento 22 de la Sentencia Plenaria Casatoria n. ${ }^{\circ} 1-2017 / C I J-433$, del 11 de octubre de 2017 , en la que se dispone que la prueba indiciaria es idónea y útil para suplir las carencias de la prueba directa.

En esa línea, Fidel Rojas (2016, pp. 215-241) resalta la correcta valoración judicial de los indicios realizados por la Sala Penal Permanente de la Corte Suprema de Justicia de la República en el Recurso de Apelación n. ${ }^{\circ}$ 06-2013-Lima, del 4 de diciembre de 2013, en cuyo décimo fundamento jurídico se precisa que, mediante la evaluación conjunta de la prueba indiciaria, es posible llegar a la resolución de condena de un delito funcionarial o de corrupción, lo cual conlleva a enervar el derecho a la presunción de la inocencia.

\subsection{Enfoque del derecho penitenciario}

a. Es pertinente un nuevo enfoque del beneficio penitenciario cuyo fundamento sea el principio del fomento de las competencias del sentenciado; vale decir, que el cumplimiento de la pena o el acceso de beneficios penitenciarios por parte de los sentenciados sean considerados en la elaboración de proyectos con fines sociales o asistenciales, basados en sus competencias, formación profesional y experiencia en la administración pública, pues, generalmente, quienes incurren en delitos de corrupción de funcionarios son profesionales o técnicos del saber humano. 
b. Se deben diseñar y promocionar campañas de prevención fundadas en las competencias profesionales o las experiencias de los sentenciados con la finalidad de sensibilizar a la población respecto a la lucha frontal contra la corrupción.

\section{CONCLUSIONES}

a. La lucha contra la corrupción constituye un reto a nivel de la comunidad nacional e internacional; por lo tanto, urge diseñar una política criminal de prevención, detección, investigación, sanción y erradicación de todo tipo de actos de corrupción. Para ello, debe partirse de un eje central que impulse reformas estructurales en las instituciones públicas y legales (iniciativas legislativas) para mejorar la administración pública, además de potentes esfuerzos colectivos desde diversos sectores de la sociedad que organicen campañas públicas para crear conciencia respecto de la lucha frontal contra la corrupción.

b. Para consolidar el Estado constitucional de derecho, esto es, la vigencia irrestricta de los derechos fundamentales y el desarrollo del país, debe promoverse un Estado eficiente y eficaz en la búsqueda del bien común (el medio para la realización de la persona). Esto será posible si se elabora un proyecto nacional y un plan de gobierno con objetivos concretos a corto, mediano y largo plazo. Ahora bien, uno de los ejes del proyecto nacional debe ser la implementación de una política criminal de lucha frontal contra la corrupción, la cual debe estar diseñada sobre los principios que hemos propuesto en los diversos niveles (normativa internacional, constitucional y política criminal preventiva) y enfoques del derecho (penal, procesal penal y penitenciario). 


\section{REFERENCIAS}

Annan, K. (2004). Prefacio. En Oficina contra la Droga y el Delito de las Naciones Unidas, Convención de las Naciones Unidas contra la Delincuencia Organizada Transnacional y sus Protocolos (pp. iii-iv). Naciones Unidas. https://www.unodc.org/documents/treaties/UN TOC/Publications/TOC\%20Convention/TOCebook-s.pdf

Arismendiz, E. (2018). Manual de delitos contra la Administración Pública: cuestiones sustanciales y procesales. Instituto Pacífico.

Borja, E. (2011). Curso de Política Criminal. Tirant lo Blanch. http:// nunezdearco.com/PDF/politica\%20criminal\%20BORJA.pdf

Burneo, J. (2009). Corrupción y derecho internacional de los derechos humanos. Derecho PUCP, (63), 333-347. https://revistas.pucp.edu. pe/index.php/derechopucp/article/view/2981/2876

Carpio, J. (2013, 15 de septiembre). Cómo funciona la mente de un corrupto: cuando los incentivos de lucro valen más que la ética. RTVE. https://www.rtve.es/noticias/20130915/como-funciona-mente -corrupto/746221.shtml

Casell, M. (2004). La política criminal. Editorial Félix Varela.

Congreso de la República (2020). Constitución Política del Perú [Promulgada el 29 de diciembre de 1993]. Congreso de la República. https://www.congreso.gob.pe/Docs/files/constitucion/constitucion 2020web-10-12-2020.pdf

Consejo Internacional de Políticas de Derechos Humanos (2009). La corrupción y los derechos humanos. Estableciendo el vínculo. Instituto Tecnológico y de Estudios Superiores de Monterrey. https://observa toricorrupcio.org/wp-content/uploads/2017/11/6.-La-corrupcio\% CC\%81n-y-los-Derechos-Humanos.-Estableciendo-el-vi\%CC\%8 1nculo.pdf

Fernández, L. (2015, 19 de octubre). Corrupción y falta de valores, las causas de la inseguridad. El Comercio. https:/elcomercio.pe/lima/ corrupcion-falta-valores-causas-inseguridad-232618-noticia/ 
Ferré, J. (2002). Corrupción y fraude de subvenciones. En Ferré, J. (edit.), Fraude de subvenciones comunitarias y corrupción (t. 1). Delitos financieros, fraude y corrupción en Europa (vol. I, pp. 11-26). Edición Universidad de Salamanca.

Lama, P. de la (2002). Asistencia mutua en la lucha contra los delitos financieros, fraude y corrupción. En Ferré, J. (edit.), Fraude de subvenciones comunitarias y corrupción ( $t$. 1). Delitos financieros, fraude y corrupción en Europa (vol. 1, pp. 331-336). Ediciones Universidad Salamanca.

Luzón, D. (2016). Derecho penal. Parte general. Tirant lo Blanch.

Macedo, F. (2015). Los actos de corrupción como violaciones de derechos humanos. Una argumentación desde la teoría del discurso racional de Robert Alexy [Tesis de maestría, Pontificia Universidad Católica del Perú]. https://tesis.pucp.edu.pe/repositorio/bitstream/handle/ 20.500.12404/6485/MACEDO_BRAVO_FRANCISCO_ACTOS_ CORRUPCI\%c3\%93N.pdf? sequence $=1$ \&isAllowed $=\mathrm{y}$

Oficina del Alto Comisionado de las Naciones Unidas para los Derechos Humanos (2020, 1 de septiembre). El ACNUDH y la buena gobernanza. Naciones Unidas. https://www.ohchr.org/sp/Issues/Develop ment/GoodGovernance/Pages/GoodGovernanceIndex.aspx

Orrego, C. (2018, marzo-abril). La corrupción: cáncer de la sociedad. El Mundo de Mañana. https://www.elmundodemanana.org/revis tas/2018/marzo-abril/la-corrupcion-cancer-de-la-sociedad

Poder Ejecutivo (2018, 22 de abril). Decreto Supremo n. ${ }^{\circ}$ 042-2018-PCM. Decreto Supremo que establece medidas para fortalecer la integridad pública y lucha contra la corrupción. Diario Oficial El Peruano, 3-7. https://busquedas.elperuano.pe/download/url/decreto-supremoque-establece-medidas-para-fortalecer-la-int-decreto-supremo-n -042-2018-pcm-1639860-1

Quiroz, A. (2013). Historia de la corrupción en el Perú. Instituto de Estudios Peruanos.

Rojas, F. (2016). Aspectos problemáticos en los delitos contra la administración pública. Instituto Pacífico. 
Ugaz, J. (2010). Algunos apuntes sobre la corrupción. Ius et Veritas, 20(40), 370-379. https://revistas.pucp.edu.pe/index.php/iusetveritas/article/ view/12160/12725

Ugaz, J. y Hava, E. (2016). Cómo definir la gran corrupción. En Zúñiga, L. (dir.), Ley contra el crimen organizado (Ley n. ${ }^{\circ}$ 30077). Aspectos sustantivos, procesales y de ejecución penal (pp. 275-298). Pacífico Editores.

Vásquez, I. (2018, 22 de abril). El costo de la corrupción que pagan los peruanos. Perú 21. https://peru21.pe/politica/costo-corrupcionpagan-peruanos-404394-noticia/?ref=p21r

Zúñiga, L. (2001). Política criminal. Editorial Colex. 